\title{
Por uma teoria da modernidade em Poesia Ingênua e Sentimental
}

\author{
For a theory of modernity in On Naïve and Sentimental Poetry
}

\author{
Géssica Góes Guimarães Gaio \\ gessicagg@yahoo.com.br \\ Professora Adjunta \\ Universidade do Estado do Rio de Janeiro \\ Avenida Doutor Mário Guimarães, 1118, apt. 1310, Centro \\ 26255-230 - Nova Iguaçu - Rio de Janeiro \\ Brasil
}

\begin{abstract}
Resumo
Poesia Ingênua e Sentimental figura atualmente como uma das reflexões mais instigantes do poeta alemão Friedrich Schiller. Embora o dramaturgo tivesse como interesse imediato ponderar acerca das formas de sentir e produzir o belo, sobretudo, na poesia e na dramaturgia, o impacto que o texto causou em sua própria comunidade intelectual e a recepção destas ideias ao longo dos séculos XIX e XX o tornaram significativo para investigar o conceito de história que permeava o debate estético, bem como analisar a construção da identidade moderna no bojo deste processo histórico. O objetivo deste trabalho consiste em analisar o tratado estético de Schiller tencionando compreender como sua proposta é constituinte de uma experiência temporal notadamente moderna; assim como ponderar acerca de sua contribuição para a construção da identidade do homem moderno e investigar sua relação e influência em um ambiente cultural no qual a criação intelectual era cada vez mais associada a um procedimento reflexivo.
\end{abstract}

\section{Palavras-chave}

Modernidade; Historiografia; Clima histórico.

\begin{abstract}
On Naive and Sentimental Poetry currently figures as one of the most intriguing reflections of the German poet Friedrich Schiller. Although the dramaturge had the immediate interest of considering the forms of feeling and producing beauty, in particular on poetry and theater, the impact of this treatise on its own intellectual community and the reception of these ideas throughout the nineteenth and twentieth centuries made it meaningful to investigate the concept of history coetaneous to that aesthetic debate and to analyze the construction of the modern identity in the midst of this historical process. This work aims to analyze Schiller's aesthetic treatise looking forward to understand how his proposal is part of a typically modern temporal experience; as well as to concern about its contribution to the construction of the identity of this modern man and to investigate its relation and influence in a cultural atmosphere in which the intellectual creation was increasingly associated to a reflexive procedure.
\end{abstract}

\section{Keywords}

Modernity; Historiography; Historical atmosphere.

\section{Recebido em: 23/9/2016}

Aprovado em: 3/5/2017

* Esta pesquisa recebeu financiamento concedido pela Capes. 


\section{Schiller e o "Outro"}

Como é que, sendo em tudo o que é natureza infinitamente suplantados pelos antigos, podemos justamente aqui homenagear a natureza num grau mais elevado, apegar-nos a ela com afeição e mesmo abraçar o mundo inanimado com a mais calorosa sensação? (SCHILLER 1991, p. 55)

Poesia Ingênua e Sentimental ${ }^{1}$ foi publicado pela primeira vez como artigos separados na revista Die Hören, entre 1795 e 1796. Posteriormente, cerca de quatro anos mais tarde, Schiller providenciou a sua publicação conjunta, cuja organização e conteúdo chegaram até nós. A influência desse texto na vida intelectual da Alemanha, na passagem dos setecentos para os oitocentos é notória, e sua recepção ao longo da tradição literária e intelectual ocidental já figurou como matéria de interesse para inúmeros germanistas, com destaque para os trabalhos de Peter Szondi e Hans Robert Jauss (SHARPE 1995). Não obstante, este ainda se mantém como um dos trabalhos mais estimulantes de Schiller, sobretudo pela complexidade das categorias propostas no ensaio e sua conexão tão íntima com o contexto intelectual no qual foi produzido.

Especialmente em território brasileiro, este trabalho ainda merece atenção, e nos interessa exatamente uma reflexão acerca da relação entre as ideias ali apresentadas e o debate intelectual de sua época - para além de sua contribuição para a caracterização da poética clássica e da romântica -, a fim de investigar a respeito da concepção de história, de homem e de modernidade que Schiller formulou em embate com sua própria experiência. Embora não se trate de um texto historiográfico tout court, ainda assim nos parece pertinente levar a curso a sugestão do historiador brasileiro Valdei Lopes de Araujo a respeito de uma "analítica da historicidade", através da qual as diversas formas de conhecimento do passado devem ser enraizadas no próprio tempo histórico. Sendo assim, é partilhando desta postura analítica que pretendemos trilhar por entre as concepções de arte e de história que movimentaram a reflexão do poeta.

A referência à carta de Goethe a Eckermann, em 21 de março de 1830, nos parece incontornável para iniciar a reflexão:

O conceito de poesia clássica e romântica, que agora corre o mundo todo e causa tanto conflito e divergência, provém originalmente de mim e de Schiller. Na poesia, tinha eu por máxima o procedimento objetivo e pretendia que apenas este valesse. Schiller, porém, que atuava de forma inteiramente subjetiva, considerava a sua maneira a correta, e para defender-se de mim, escreveu o ensaio sobre poesia ingênua e sentimental. Demonstrou-me que eu próprio, contra a vontade, sou romântico e que, pelo predomínio da sensibilidade, minha Ifigênia não é assim tão clássica e tão no sentido antigo como talvez se pudesse crer. Os Schlegel aproveitaram a ideia, de modo que agora ela se difundiu pelo mundo inteiro, e todos falam de classicismo e romantismo, nos quais há cinquenta anos ninguém pensava (GOETHE apud SCHILLER 1991, p. 23). 
As palavras de Goethe sintetizam em grande maneira a recepção que as ideias de Schiller encontraram em solo germânico. Fica acentuada aqui, sobretudo, a dicotomia entre clássico e romântico que por muitas décadas forneceram a tônica do debate acerca de PIS. Contudo, mesmo que Schiller tivesse encontrado motivação para buscar tal entendimento em seu relacionamento com Goethe e as diferentes maneiras que encontravam para produzir sua arte, em contrapartida, nos parece que este aspecto não deveria ser maximizado.

O ano do início da correspondência entre Schiller e Goethe foi também o da elaboração dos artigos que deram origem ao Poesia Ingênua e Sentimental. Já na famigerada primeira carta de Schiller a Goethe, de 23 de agosto de 1794, o remetente de Iena traçou o perfil intelectual de seu destinatário destacando sua capacidade em aproximar-se da natureza: "O senhor concentra toda a natureza, a fim de receber uma luz de cada elemento; na totalidade dos fenômenos dela o senhor procura a explicação para o indivíduo". Esse traço do espírito poético de Goethe aguçou o interesse de Schiller, que considerava essa habilidade um verdadeiro dom, o dom do gênio que, inclusive, julgava ausente em sua própria forma de poetizar. Schiller teria ficado maravilhado com a facilidade com que Goethe transformava o complexo em fluidez, como ele era capaz de expressar o absoluto de forma tão simples. Na mesma carta, ele concluiu: "o senhor teve trabalho a mais, pois da maneira como passou da visão à abstração, teve de transpor de volta conceitos em intuições e transformar ideias em sentimentos, pois só através deles o gênio pode produzir" (GOETHE; SCHILLER 2010, p. 28-27).

Essa passagem nos parece central para o entendimento da tese presente nos artigos que compõem PIS. Se por um lado Schiller entende a poesia de Goethe como ingênua, porque preserva uma relação próxima com a natureza, algo que considera incapaz de realizar em sua própria produção artística, por outro não se escusa de enfatizar que esta relação não é imediata, ela não é natural, e sim fruto de um laborioso artifício intelectual - por mais que tal esforço não cause fadiga - de transformar ideias e conceitos em sentimentos e intuições. Isto é, a relação de Goethe com a natureza não era espontânea, não poderia ser, pois seu pertencimento histórico lhe permitia desenvolver primeiramente as capacidades da razão e seu gênio Ihe possibilitou transformálas em forças da natureza.

No conto "Hora difícil", de 1905, um século após a morte de Schiller, Thomas Mann trouxe as inquietações de Schiller de volta à vida. Sua condição enferma, o cansaço de seu corpo debilitado, as modestas instalações de sua casa, as ideias em tempestade e o Outro, aquele que Ihe era tão próximo, mas ainda assim o espelho invertido, a imagem de quem ele jamais fora ou pudera ser, "aquele que amava com terna inimizade". Talvez Poesia Ingênua e Sentimental tenha contribuído para a construção desta imagem: Goethe como o poeta ingênuo e genial, posto que sua arte mantinha uma relação direta com 
a natureza; Schiller como o poeta sentimental, ${ }^{2}$ atordoado, cuja poesia e teatro eram filhos do sofrimento, da dor.

Era preciso afirmar e definir sua própria natureza e arte diante da do Outro. O Outro seria maior? Se fosse, em quê, e por quê? Se vencesse, seria por ter suado sangue? Se perdesse, seria uma queda trágica? Não, o Outro não era herói; talvez um deus. Mas era mais fácil ser deus que ser herói (MANN 2000, p. 202).

Seria mais fácil ser ingênuo do que sentimental? Seriam realmente as duas categorias apenas uma caracterização do modo de Goethe e Schiller sentirem e viverem a arte? Por mais envolvente que seja essa tese, não consiste em nosso interesse sustentá-la. Mais do que sua relação com o amigo de Weimar, importava a Schiller o estatuto de seu tempo, a necessidade de conferir sentido à arte e legitimá-la como promotora da educação do gênero humano.

\section{A Querelle des anciens et des modernes e a consciência do tempo}

Ainda pairava no mundo intelectual europeu do século XVIII o que se convencionou chamar de "querela entre antigos e modernos", uma série de debates que tomaram, principalmente, os salões franceses e cujo tema central era a contenda entre defensores e detratores dos feitos dos antigos e dos modernos. O historiador brasileiro Antonio Edmilson Rodrigues dedicou o último capítulo de Tempos Modernos à análise da "querela", e sua reflexão sobre a construção da ideia de moderno através da elaboração do seu outro como antigo está em acordo com a proposição de Hans Robert Jauss, para quem a querela consiste em um topos literário, que se repete em tentativas periódicas de estabelecer o novo em contraste com o precedente (RODRIGUES; FALCON 2000 , p. 247). Joan DeJean (2005, p. 39), por sua vez, sugere uma analogia entre a querela francesa do século XVII e as guerras culturais no âmbito da literatura norte-americana da década de 1990 para propor uma nova concepção de fin de siécle, na qual seja possível perceber essas disputas entre o novo e a tradição como uma faceta da tensão intrínseca à noção de progresso. ${ }^{3}$

Desde o século XIV, a filosofia humanista atribuiu à Antiguidade uma função modelar na cultura e pensamento europeu; seja através de uma atitude mediada pela imitação, inspiração ou emulação, a Antiguidade Clássica grecoromana exerceu um papel paradigmático para a cultura ocidental. Esse antigo foi convertido em tradição clássica e a construção da modernidade foi forjada em contínua negociação com o legado greco-romano. A ideia de uma tradição conferiu inteligibilidade à produção intelectual e estética dita classicista, bem como tornou inevitável o reconhecimento da grandiosidade dos antigos como

\footnotetext{
2 Schiller usou o termo Sentimentalisch para distinguir o seu sentimental da corrente literária do Empfindsamkeit, "sentimental" no sentido de "emotivo". O termo escolhido por Schiller tem como objetivo afastá-lo da tendência de fins do século.

${ }^{3}$ A autora salienta que mesmo Charles Perrault em seu Parallèle des Anciens et des Modernes compreendeu que seu argumento sobre a superioridade dos modernos apontava para um problema cultural, afinal, o que poderia emergir após a "perfeição"? Ao considerar o seu próprio tempo como o ápice do progresso, Perrault lançava a dúvida sobre os tempos vindouros (DEJEAN 2005, p. 43).
} 
justificativa do desenvolvimento dos modernos. Pensar em uma tradição clássica nesses termos seria pressupor que, independentemente da linearidade, um só tempo envolve as duas pontas do debate.

Na Academia Francesa, em finais do século XVII, Charles Perrault, em Parallèle des Anciens et des Modernes, falava em nome dos modernos e da inegável "lei do progresso intelectual". A grandiosidade dos antigos era atestada por seus inúmeros feitos, mas a superioridade dos modernos poderia ser comprovada pelo simples fato de que os antigos não tiveram antecessores, já os modernos contaram com toda a produção intelectual e cultural da Antiguidade. A metáfora de Bernardo de Chartres dos "anões em ombros de gigantes" ainda era considerada apropriada para ilustrar o respeito que os modernos tinham em relação aos antigos, bem como a certeza da proeminência dos novos tempos. No Século das Luzes, com a materialização do progresso técnico e intelectual na Enciclopédia, os tempos modernos aparentavam aos seus defensores nada menos que uma realidade melhor. A "querela" ganhou uma nuance no século XVIII, pois se $o$ ideal de homem e liberdade que predominou entre os gregos ainda comovia os intelectuais, por outro lado, até que ponto os modernos estavam dispostos a abrir mão do avanço técnico e intelectual que a humanidade havia alcançado? 0 dilema que motivou o ensaio de Schiller estava em estreita conexão com essa pergunta. De acordo com Rodrigues (2000, p. 273), no século XVIII, o debate permaneceu, mas "a vitória dos modernos sem a derrota dos antigos" construiu a base para o progresso iluminista e conferiu sofisticação à produção cultural.

Assim como a Aufklärung, em solo germânico a "querela" chegou um pouco depois de seu début nos salões franceses. Foi somente no último quartel do século XVIII que este debate foi acolhido entre os intelectuais, sobretudo por Herder, Schiller e Friedrich Schlegel. Segundo Maike Oergel, germanista e professora da Universidade de Nottingham, a identidade moderna germânica emerge justamente da definição da modernidade europeia no seio desta disputa com o passado, na qual a "querela" pode ser resumida ao embate entre uma perfeição realizada pelos antigos e o processo de conquista da perfectibilidade pelos modernos.

Oergel nos ajuda a lembrar que a resposta predominante na França para esta questão apontava para uma concepção do tempo histórico como processual e progressista. Entre os alemães, o debate seguiu por outra vereda. Herder, por sua vez, já bastante sensível às ideias que posteriormente seriam denominadas como Historismus, buscou, através de uma perspectiva histórica, uma nova compreensão para a "querela" - pelo menos no que dizia respeito às artes. Segundo sua análise, o belo seria relativo a cada tempo e cultura. Ainda muito influenciado pela Aufklärung, Herder não excluiu de sua noção particularizada do belo a existência do belo universal como um ideal, que demandaria padrões universais e a concepção de que há certa normatividade na natureza humana.

Mas tal definição é problemática mesmo para o filósofo, pois a acepção da "constância da natureza humana" associada a uma medida tipicamente moderna, tal qual o "progresso", seria o suficiente para afirmar a superioridade dos modernos por questões quase que matemáticas. Todavia, o historicismo 
de Herder tende a pensar a mudança de maneira qualitativa, primando pela compreensão das características específicas de cada manifestação cultural, através da concepção da natureza como fonte de criação e espontaneidade para a história (CALDAS 2007, p. 51). Dessa forma, os valores clássicos deixariam de ocupar um lugar absoluto nesta história, bem como a "mudança" em si passaria a ser a principal característica do processo. Diferentemente do que ocorreu na França, Herder, Schiller e Schlegel estavam mais interessados em relacionar antigos e modernos do que confrontá-los.

A contribuição das ideias historicistas para o desdobramento da "querela" entre os alemães não poderia ser obliterada, afinal por intermédio desta nova maneira de se relacionar com o passado que Herder pôde articular sua ideia de belo com o imperativo iluminista do progresso. Seu ideal de beleza poderia ser compreendido como a perfeita particularidade de uma expressão cultural, que mantém até mesmo uma normatividade interna, porém apenas enquanto aquela cultura na qual se insere ainda for orgânica. Toda vez que isso acontecer na história da humanidade, certamente será algo grandioso, e, assim, merecedor de memória e constituinte do ideal que a humanidade deve seguir. O objetivo não seria estabelecer um padrão, mas reconhecer na história a realização de algo essencial, único, filho de seu tempo e, nessas condições, verdadeiro. Por isso, Sófocles e Shakespeare ainda seriam pertinentes, mesmo para uma Europa oitocentista.

A imitação dos gregos seria inútil e esvaziada de sentido, pois ela teria

102 como pressuposto um ideal estático de homem e cultura. Herder rejeita os dois lados da "querela", porque ambos representam pontos de vista a-históricos. Suas ideias apontam para uma perspectiva que não se encerrasse em um passado acabado, ou em um futuro carente de significado, mas no presente e nas necessidades da cultura de um povo.

Para Oergel, quando Schiller e Schlegel encetaram a discussão sobre a relação entre os antigos e os modernos, a partir da segunda metade da década de 1790, o historicismo já se encontrava integralmente presente em seu argumento. O artigo de Schiller estaria, portanto, fundamentado na concepção de que a arte é profundamente diferente em cada período histórico, porque o ambiente histórico e intelectual interfere decisivamente nas condições de sua produção. PIS poderia ser compreendido entre o segundo e o terceiro significados de "moderno" elencados por Gumbrecht (1992, p. 81): a concepção de moderno como "novo" e oposta ao "antigo" e a ideia de moderno como "transição" como um "futuro passado". Sendo assim, a comparação entre antigos e modernos somente seria possível em um nível estrutural, e a essa tarefa Schiller teria se lançado em PIS.

\section{A dialética do ingênuo e do sentimental}

A querela configurou o pano de fundo para que Schiller elaborasse os conceitos de poesia ingênua e poesia sentimental. Todavia, seu objetivo era caracterizar a produção poética através do seu modo de sentir, por isso evitou as denominações clássico e moderno. Sua tentativa era criar algum entendimento 
a partir da concepção de que essas duas maneiras distintas de poetizar são motivadas por formas de sentir também específicas.

De acordo com Schiller (1991, p. 55), a relação dos gregos com a natureza era completamente diferente da moderna, aos gregos "a natureza parece interessar mais seu entendimento e sua avidez de saber do que seu sentido moral; não se apega a ela com afeição, com sentimentalismo, com doce melancolia, como nós outros modernos". Essa diferença é o ponto de partida do ensaio, os gregos - principais representantes do modo de sentir ingênuo teriam como base de sua relação com a natureza o seu amor pelo conhecimento; já os modernos procuravam na natureza uma referência moral, e a percepção do afastamento entre o homem e a natureza produz o sentimento de melancolia que atormentara Schiller e grande parte dos seus contemporâneos. Sua tese sustentava a existência de apenas duas formas de poetizar, e essas duas formas estariam intrinsecamente associadas às duas maneiras distintas de o poeta se relacionar com a natureza - ser natureza ou buscar a natureza perdida -, testemunha ou vingador da natureza.

Lothar Pikulik (2009, p. 81), germanista e professor emérito da Universidade de Trier, propôs um entendimento acerca das categorias empregadas por Schiller através de um movimento analítico que denominou como "dialética do sentimentalismo". Em seus termos, a antinomia entre o ingênuo e o sentimental poderia ser pensada através da dinâmica entre o sentimento da natureza e a desnaturalização do sentimento no fazer poético moderno. Ao historicizar a busca pela natureza como um imperativo para o idealismo alemão em fins dos setecentos, encontraríamos em Jean-Jacques Rousseau uma das mais importantes influências para o trabalho de poetas como Kleist, Klopstock e do próprio Schiller. O retorno à natureza para estes poderia então ser compreendido em compasso com as mudanças na vida de várias sociedades europeias, intensificadas pelo crescimento das cidades e da atividade comercial e manufatureira, o afastamento da vida campesina e a experiência paradoxal da solidão em plena sociedade. Peter Szondi (1991, p. 47) empreendeu uma importante investigação sobre a dialética dos conceitos de ingênuo e sentimental e concluiu que, para Schiller, sentimental não era oposto a ingênuo, uma vez que, na analítica dos conceitos, ingênuo seria contrário ao pensamento reflexionante, e sentimental, o acordo entre a ingenuidade perdida e a razão. Em outras palavras, o sentimental seria o novo ingênuo, mas dessa vez já imbuído de seu ideal.

O que caracterizaria a atitude sentimental seria o interesse do homem moderno pela natureza. Schiller chegou mesmo a afirmar que nossa maneira de nos comovermos com a natureza se assemelharia à sensação de um enfermo em relação à saúde. O emprego de uma metáfora médica é muito interessante, pois denota a aguda insatisfação de Schiller com o seu tempo e sua cultura, mas também seu otimismo pela possibilidade da cura. Igualmente pertinente seria lembrar que no subtítulo de sua tese de doutoramento, Crítica e Crise, o historiador alemão Reinhart Koselleck (1956) se propunha a um estudo sobre a "patogênese" do mundo burguês. Ora, parece que a alegoria do nascimento enfermo da modernidade atravessou a tradição alemã e tornou-se mais uma 
maneira paradigmática de compreender tal processo histórico, sobretudo em oposição a um otimismo quimérico no progresso e na razão que emanava dos salões franceses. O que Pikulik (2009, p. 84) destaca com muita propriedade é que, se para Schiller o homem moderno encontrava-se adoentado, a atitude sentimental face ao mundo e sua arte assumiria certa função terapêutica.

Essa terapia estaria a serviço dos indivíduos que compartilhavam aquela experiência histórica e não apenas aos poetas e artistas. Lothar Pikulik assinala que o conceito de sentimental empregado por Schiller não se reduz à poesia, pois ele teria atribuído-Ihe uma atitude radicalmente transformada do homem civilizado a respeito da natureza, fundada na forma íntima do espírito. Nesse aspecto, a análise do germanista ganha bastante densidade, sobretudo na formulação da tese de que o sentimentalismo seria um "pietismo secularizado", no qual o caráter comum entre o sentimentalismo e o pietismo convergiria no surgimento de uma experiência íntima com o mundo ao redor, por meio da valorização da subjetividade (BERLIN 1997; WEBER 2004).

Nesse movimento de interiorização, seja da experiência religiosa, seja da observação do eu e do mundo, o indivíduo moderno estaria face ao procedimento que o torna sujeito: a autorreflexão. Como consequência direta, a subjetividade passaria a participar diretamente na representação do objeto da observação (ARAUJO 2011). É nessa operação que a experiência da natureza para o poeta sentimental converte-se na experiência de si mesmo. Graças ao caráter reflexivo de sua razão, ao conhecer seu objeto, ao produzir conhecimento, ao criar a arte, o homem moderno se auto-reflete. Neste processo de interiorização, o sujeito transforma-se em espectador de si mesmo.

Para Pikulik, no ensaio Schiller expressava sua crítica e insatisfação com a cultura. Não obstante, se atenuarmos o valor pejorativo que o emprego da crítica contraiu nesta proposição e pensarmos a partir de uma perspectiva na qual a crítica seja o esforço de pensar os limites da razão e do conhecimento, podemos alargar um pouco mais a dimensão do projeto schilleriano. Uma vez que o poeta visava não somente apontar as mazelas de seu tempo, como também indicar caminhos a serem trilhados pelo homem moderno, o seu ensaio adquire contornos de uma crítica de ares kantianos, na medida em que sua avaliação não se restringe ao ateliê do poeta, mas se amplia para as formas de conceber o conhecimento e sua representação nas artes. ${ }^{4}$

Se a modernidade estava enferma, para Schiller a boa saúde poderia ser reestabelecida através da recuperação de um traço ingênuo, de uma reconciliação com a natureza. Sua resposta para a antinomia aparentemente insolúvel entre sensibilidade e espírito seria a conciliação entre ingenuidade e reflexão. O caminho natural da criação na poesia ingênua se oporia ao caráter racional distintivo do processo de modernização, dessa forma, a espontaneidade do poeta ingênuo, da qual flui a beleza em comunhão com a natureza, deveria

\footnotetext{
${ }^{4} \mathrm{~A}$ influência da filosofia de Immanuel Kant sobre o pensamento de Schiller é notável e muito mais ampla do que a referência acima. A Crítica da faculdade do juízo foi central para a formulação dos princípios estéticos da reflexão schilleriana, como, por exemplo, a teoria do sublime. Mas devido às dimensões deste artigo, este ponto não consiste em nossa prioridade.
} 
ser emprestada ao poeta moderno, de maneira que na criação sentimental a beleza pudesse ser resultado da consciência, da razão que transformou a natureza em Ideia. ${ }^{5}$

Para sustentar seu argumento acerca da naturalidade da poesia ingênua, Schiller (1991, p. 51) chegou a afirmar que todo gênio seria ingênuo. O gênio - compreendido como o tradutor da natureza - não poderia travar com ela outra relação se não da ingenuidade. Assim sendo, o gênio seria aquele cuja sensibilidade o torna mais suscetível que os demais homens aos mistérios da natureza. Mesmo ingênuo, o gênio poderia também surgir na modernidade, sendo a melhor chance de a humanidade estabelecer um vínculo verdadeiro com a natureza perdida, entretanto, nem mesmo o gênio estaria imune ao seu tempo, e até mesmo o seu caráter poderia ser corrompido. "Ignorando as regras, essas muletas da fraqueza e mentoras do erro, e orientado apenas pela natureza ou pelo instinto, o seu anjo da guarda, caminha com tranquilidade e segurança por todas as ciladas do falso gosto" (SCHILLER 1991, p. 51); para o gênio, as normas são entraves, na verdade ele as desconhece, pois não carece de medidas para preparar uma bela obra, por isso ignora receitas e desafia os cânones. O gênio é o arauto da natureza não somente porque soluciona o complexo com simplicidade, mas, sobretudo, porque ele o faz com graça - uma leveza de gestos e forma que só o espírito ingênuo seria capaz de expressar.

Já o poeta sentimental tem sua experiência marcada pela ruptura entre o homem e a natureza, ele não pode mais atingir a plenitude do mundo natural, pois sua relação com a natureza foi dissolvida pelo processo civilizador, a cultura é sua cicatriz, lembrando-Ihe frequentemente que a espontaneidade foi perdida, em benefício do desenvolvimento de sua consciência. A naturalidade esvaída foi compensada pela capacidade de reflexão, através da qual o poeta seria capaz de acessar a natureza de maneira ainda mais plena, como uma Ideia. Essa relação subjetiva proporcionaria ao poeta sentimental realizar em sua obra a natureza não como apresentação da realidade, mas como busca de um Ideal. "À medida que a natureza foi, pouco a pouco, desaparecendo da vida humana como experiência e como sujeito (agente e paciente), nós a vemos assomar no mundo poético como Ideia e como objeto" (SCHILLER 1991, p. 56). É essa busca consciente de um Ideal do gênero humano que assegura aos modernos a superioridade, na contenda armada por Schiller.

Na poesia ingênua, a sensibilidade elabora uma imagem da natureza completamente baseada na experiência; já na poesia sentimental, a razão consegue formar um conceito de natureza mediado pela reflexão, este conceito ultrapassa as limitações dos sentidos e se expande no infinito da consciência. Segundo Márcio Suzuki, a poesia sentimental, tal como pensou Schiller, é

\footnotetext{
${ }^{5}$ Erwin Panofsky nos ajuda a historicizar o sentido deste conceito desde sua primeira utilização por Platão, quando a "Ideia" remetia a valores metafísicos e universais, intransponíveis pela obra de arte. Contudo, Panofsky acreditava que ainda na Antiguidade, provavelmente nos trabalhos de Cícero, já seria possível perceber um uso do conceito com a conotação que o aproxima da atividade artística, a saber, como "representações ou intuições que residem no espírito do próprio homem" (PANOFSKY 1994, p. 12). Aqui o conceito de "ideia" é empregado como "conceito da razão", em alusão à apropriação da filosofia de Kant operada por Schiller. Na Crítica do Juízo, Kant explica que os conceitos da razão não podem ser expostos, uma vez que não são frutos da experiência, fenômenos ou mediados por algum objeto, são, portanto, representações de ideias morais.
} 
progressiva, pois seu a priori é o aperfeiçoamento infinito da razão humana, enquanto que a poesia ingênua opera em uma perspectiva de aperfeiçoamento limitada pela finitude da natureza. Para Suzuki (apud SCHILLER 1991, p. 22), o ensaio de Schiller é um elogio ao progresso: "Não é com revolta contra os feitos do entendimento e contra o estado em que se acha a sociedade, mas é progredindo que se recupera a sensibilidade e a verdadeira natureza". ${ }^{6}$

A Ideia de natureza se torna mais complexa e dinâmica do que sua realidade sensível. O poeta sentimental tem em seu benefício a possibilidade de recorrer ao infinito para produzir a sua arte, enquanto a experiência da natureza do poeta ingênuo é limitada. Embora o poeta sentimental saiba que a totalidade é um interdito, ainda assim, mantém o absoluto como sua meta e é dessa busca pelo Ideal que emana a beleza da poesia sentimental. Se a naturalidade das formas e a espontaneidade da expressão caracterizariam o belo ingênuo, a reflexão e a idealização da natureza seriam os traços distintivos da beleza sentimental. Neste momento, configura-se uma inflexão relevante, pois a cultura, que a princípio foi avaliada como a responsável pelo afastamento entre o homem e a natureza, transformar-se-ia em aspecto imprescindível da poesia sentimental e motivo de sua superioridade em relação à poesia ingênua. ${ }^{7}$

\section{O sentimental como uma categoria analítica para a Modernidade}

A categoria "sentimental", proposta por Schiller, nos obriga a pensar algumas questões em torno da cultura burguesa, então em expansão entre os 106 reinos germânicos. Thomas Mann (2012) não encontrou grandes dificuldades ao afirmar o caráter burguês da produção literária de Goethe, e nós também não teríamos maiores constrangimentos em fazê-lo acerca da reflexão teórica aqui analisada. Contudo, foi o próprio autor de A Montanha Mágica quem nos advertiu sobre o seguinte aspecto: Goethe pode ser considerado o grande representante intelectual e cultural do mundo burguês, mas foi Schiller quem entre os alemães melhor apresentou seu ímpeto humanitário-revolucionário. Como um "patriota da humanidade", Schiller representaria o ideário político burguês, sobretudo pelo viés democrático-liberal. Sua inserção na cultura burguesa foi mediada por esse otimismo libertário de viés nitidamente político, mas pouco comprometido com a reflexão social (MANN 2012).

Além da perspectiva política apontada acima, uma segunda característica fundamental do processo de modernização em curso na Europa ocidental, a saber, a racionalização das mais diversas esferas da vida social também configura como um dos principais distintivos da poesia sentimental. O poeta sentimental é consciente de que sua criação é um produto do artifício, produto de uma mente capaz de criar a partir de suas competências cognitivas e de um instrumental conceitual e analítico que o inibe de qualquer espontaneidade,

\footnotetext{
${ }^{6}$ Hans Robert Jauss já havia afirmado anteriormente que Schiller foi o primeiro a conferir um valor positivo à ideia de "moderno" na tradição alemã (OERGEL 2006, p. 28).

7 Schiller (1991, p. 57) destacou que assim como existem poetas modernos que exprimem um sentimento ingênuo em sua arte, alguns poetas antigos também produziram obras sentimentais. Seu principal exemplo é Horácio, considerado poeta de uma época decadente, o qual exaltou a tranquilidade perdida, e que seria o fundador do gênero sentimental.
} 
porém o habilita a superar aquilo que antes era apenas natureza; através do procedimento racional, a poesia sentimental pode produzir o Ideal.

Escusado dizer que tal procedimento se expandiu para além da pena dos dramaturgos. O entendimento de que o trabalho intelectual pressupunha um esforço de universalização se tornara uma assertiva bem-aceita nos mais variados círculos científicos e acadêmicos. O historiador profissional também se apropriou do mesmo discurso para legitimar a disciplina no curso do século XIX, a alegação de um trabalho empírico, confiável, fundamentado em pesquisa rigorosa das fontes e livre das paixões é mais um afluente dessa cultura racionalista e burguesa por excelência. A historiografia que se consolidou nas universidades germânicas no século XIX certamente poderia ser chamada por Schiller de "sentimental". Ela é sentimental na medida em que é artifício, enquanto produto da consciência de sua artificialidade e quando explora as possibilidades e limites de tal conhecimento. ${ }^{8}$

Se entendermos nesses termos a produção historiográfica dos oitocentos, então poderemos compreender que a busca pela cientificidade e imparcialidade não era apenas demanda da estrutura universitária na órbita do modelo das ciências naturais, mas também uma experiência compartilhada de crescente aburguesamento da sociedade e dos padrões de construção dos discursos acerca da realidade, entre eles o discurso sobre o passado. Podemos entender a proposta analítica de Schiller como um sinal de certa sensibilidade acerca do processo histórico no qual ele mesmo estava inserido, destarte, o poeta sentimental seria assim compreendido no bojo do processo civilizador em curso na Europa moderna. ${ }^{9}$ Contudo, a especificidade do olhar do poeta nos proporciona ainda um novo cuidado no trato da questão. A sensibilidade aguçada de Schiller captou um aspecto desta experiência histórica que se tornou muito cara para seu argumento e nos auxilia a compreender a complexidade daquilo que denominamos como modernidade. Ao caracterizar a arte de seu tempo como sentimental, ele não apenas atentava para o caráter racional da obra, como também para a vocação estética dessa produção. Ora, importava a ele entender o papel da imaginação na arquitetura razão humana e ao decidir chamar sua poesia de sentimental interessava-Ihe afirmar a relevância dos sentidos para a compreensão do mundo.

\footnotetext{
${ }_{8}$ Provavelmente o melhor exemplo desta concepção de uma escrita da história sentimental seria o artigo de W. von Humboldt (2001), Sobre a tarefa do historiador, no qual o ofício do historiador é analisado através de sua dupla exigência: o trabalho com as fontes e a interpretação do processo histórico.

9 O conceito de "civilização" foi interesse de estudo de Norbert Elias, que destacou como seria possível perceber clara distinção entre os desdobramentos do processo civilizador em uma formação sócio-histórica predominantemente franco-britânica, marcada pelo artifício e pela superficialidade das relações sociais e, em outra perspectiva, a kultur alemã, cuja característica principal seria a valorização de um traço interior, particular e profundo. A utilização de palavras como "Kultur", "kultivierte" e "bildender", nos escritos filosóficos de Schiller, aponta para aspectos etimológicos que reforçam a noção de que a compreensão do que seriam a "civilização", o homem "civilizado" e o espírito "civilizador", respectivamente, não pode ser confundida com ideias predominantes na experiência das Luzes francesas como "progresso". Mas ainda assim, o uso e entendimento que Schiller atribuiu a esses termos aproximam seu significado ao que Norbert Elias reconhece como uma "função geral do conceito de civilização", como "consciência que o Ocidente tem de si mesmo" (ELIAS 1994, p. 23). Em carta a Goethe, Schiller afirmara que o amigo era possuidor de um "espírito civilizador"; em alemão, o vocábulo utilizado é "bildender", isto é, o radical da palavra, "Bild"- imagem, ideia, noção -, é o mesmo de "Bildung", cujo significado remete a um processo contínuo e inconcluso de cultivo e formação, seja do indivíduo ou de um povo (GOETHE; SCHILLER 2010, p. 29).
} 
O olhar do poeta alemão sobre o passado que o interessava como constituinte de sua identidade germânica e moderna é peculiar. Desse modo, aproximar-nos do ensaio de Schiller permitiria o contato com uma noção de história na qual tal processo descrito por Reinhart Koselleck (2006) como dissolução do topos da história magistra vitae e surgimento de uma história como singular-coletivo ainda não havia sido concluído. A fim de manter o diálogo com Koselleck, agora remontamos a sua teoria dos tempos históricos para lançar mão da noção de estratificação do tempo, que nos permitiria pensar como elementos da concepção clássica de história se articulam a aspectos prenunciados pelo conceito moderno de história, em uma dinâmica na qual mudança e recorrência conferem ao presente caráter distinto, em uma experiência na qual essas camadas do tempo se sobrepõem e se confundem no processo de sedimentação cultural.

Na formulação schilleriana, o retorno ao referencial antigo não se justificava pela imitação de seus feitos, nem pela superação de sua cultura. A luz que a Grécia clássica lançava sobre a modernidade se impunha como um imperativo ético, um dever ser, um ideal a lembrar ao homem moderno sua verdadeira vocação: "São o que nós fomos; são o que devemos vir a ser de novo. Fomos natureza como eles, e nossa cultura deve nos reconduzir à natureza pelo caminho da razão e da liberdade" (SCHILLER 1991, p. 44).

O passado assim referido abre espaço para uma experiência do tempo histórico que não se encerraria nos paradigmas em disputa, a saber, a história 108 mestra da vida ou a história processual, como um singular-coletivo. Em PIS, é estabelecida uma interessante relação entre passado e futuro, na qual o debate na esteira da "querela entre antigos e modernos" poderia adquirir nova configuração. Se antes os intelectuais nas academias francesas mobilizavam-se entre os defensores dos antigos e os partidários dos modernos, com PIS ficava estabelecida a superioridade da razão moderna, mas o traço genial somente poderia ser produzido por aquele que se aproximasse da primeira natureza, perdida no fluxo da história.

A natureza como um "dever ser" presente em todo o projeto estético de Schiller nos autorizaria a pensar como sua reflexão se insere em uma experiência histórica compartilhada naquele cenário alemão de inícios dos novecentos. 0 passado não nos é por ele apresentado como uma tábua de prescrições, nem mesmo como uma etapa superada, mas como um devir, como um imperativo, em outras palavras, como uma imposição ética. No projeto estético de Schiller, é essa imposição ética que leva à ação: o poeta, o intelectual, o indivíduo devem agir. É importante notar que até mesmo certa legitimação dos tempos modernos emerge dessa concepção da história como um "dever ser", afinal, a modernidade, como todo presente, seria o momento privilegiado para o cumprimento dessa vocação. Apesar de toda a crítica a sua sociedade e ao ataque à perfídia do mundo da política e dos interesses, Schiller ainda acreditava na eficácia de uma educação estética que pudesse contribuir para a transformação do mundo através do cultivo dos sentidos. Se o diagnóstico era desafiador, a expectativa, por sua vez, revelava maior otimismo quanto aos desdobramentos do processo 
histórico no qual ele mesmo estava inserido. Os tempos modernos têm aqui sua importância reafirmada pelo lugar privilegiado para a ação.

A reflexão de nosso poeta pode ser compreendida como uma reação a uma nova consciência do tempo, que emergiu do Iluminismo francês, sobretudo expresso na querela e em seus desdobramentos, mas que ainda não havia sido incorporada à norma linguística até então. Se com Charles Perrault a proeminência da presente face ao passado atribuiu caráter progressivo à consciência do tempo, em PIS o conceito de moderno assumiu o conteúdo não apenas de "novo", bem como de "mudança" e "transição", influenciando grandemente o léxico germânico (GUMBRECHT 1992, p. 89-92).

Se nos propusermos a um exercício analítico análogo ao empreendimento de Hans Ulrich Gumbrecht em "Cascatas de modernidade", poderemos compreender de maneira mais ampliada a importância - e até mesmo o pioneirismo - de PIS na elaboração de sentidos para o processo histórico de transformação epistemológica que caracterizaria a segunda cascata de modernidade. Na primeira experiência de modernização, o surgimento do sujeito cognoscente como um "observador de primeira ordem" configuraria uma valorização do indivíduo como produtor de conhecimento a partir da observação da natureza e do mundo que o cerca; por volta de 1800, esse observador teria vivenciado uma significativa virada epistemológica que o teria transformado em um "observador de segunda ordem", isto é, sujeito do conhecimento que ao mesmo tempo em que observa seu objeto é capaz de se auto-observar como agente da primeira observação. ${ }^{10}$ Esse sujeito autorreflexivo tem como desafios a tarefa de entender como se relacionar com experiências que são exclusivamente baseadas em conceitos, além de ter de lidar com aquilo que posteriormente foi denominado por Michel Foucault como "crise da representabilidade". ${ }^{11}$

Um exemplo instigante dessa experiência partilhada, na qual Schiller tomou lugar, reside em grande parte na obra do pintor Caspar David Friedrich, que nos convida a observar seus personagens observando o mundo, como na célebre tela do romantismo alemão "Viajante sobre um mar de névoa". Caspar David, para quem "pintar era questão de autodisciplina e 'trabalho consciente'", ou seja, um artista indubitavelmente sentimental, a reflexão filosófica nunca foi um ofício, mas ainda assim seus quadros são reveladores dessa virada epistemológica da qual estamos tratando. Suas telas nos impõem o questionamento: o que pensam os outros? Como os demais veem o mundo? Nas imagens criadas pelo pintor alemão, somos convidados a observar diferentes pontos de vista sobre a realidade. Segundo Gumbrecht (2014, p. 83-93), se tornara cada vez mais difícil para a sociedade burguesa ignorar as infinitas possibilidades e perspectivas para os sentidos e percepção da realidade. A busca por uma nova harmonia

\footnotetext{
${ }^{10}$ Embora a utilização da categoria de "observador de segunda ordem" remeta ao trabalho de Niklas Luhman, o uso que fazemos aqui está diretamente associado à apropriação de Gumbrecht (1998) em Modernização dos sentidos.

${ }_{11} \mathrm{Um}$ aspecto central desta crise causou bastante instabilidade no pensamento historicista alemão de inícios do século XIX, uma vez que a legitimação de representações múltiplas sobre o passado, sem a hierarquização de tais imagens, incorreu na crítica do relativismo total e da própria impossibilidade do conhecimento histórico. O observador que é incapaz de deixar de se observar enquanto observa o mundo já não pode assegurar o estabelecimento de uma verdade cuja validade pode ser sustentada universal e perenemente.
} 
seria mais um dos sintomas desse sujeito moderno cindido. Seguindo esta linha analítica, seria possível admitir que, no momento da escrita de PIS, Schiller se encontrava no limiar de uma modernidade em transformação. Vivendo exatamente no período de estabilização do segundo sentido deste processo de modernização, o movimento interpretativo que Schiller propôs acerca de seu tempo pode ter fornecido à tradição ocidental o primeiro esforço filosófico e estético com o objetivo de compreender a virada epistemológica em processo no mundo europeu no período do Sattelzeit. ${ }^{12}$

Em seu ensaio, Schiller utiliza as categorias de ingênuo e sentimental para pensar diferentes formas de o poeta se relacionar com a natureza, mas, ao fim da leitura, estamos convencidos de que há algo para além da preocupação com a produção artística em sua reflexão. De maneira quase intuitiva, Schiller nos diz sobre a condição mesma do intelectual em seu tempo. Assim sendo, não seria o poeta sentimental um observador de segunda ordem? Caso aceitemos esta conclusão como verdadeira, sua condição autorreflexiva seria, concomitantemente, sua maior vantagem e também o motivo de sua melancolia. A poesia sentimental é justamente aquela que não pode ser dissociada da subjetividade daquele que a produziu, e quem, senão o autor desta poesia, para apontar o caráter perspectivado de sua produção? Sem a pretensão de equiparar o poeta ingênuo a um observador de primeira ordem, outrossim consideramos pertinente compreender o poeta sentimental pari passu aos traços característicos do observador de segunda ordem, cuja produção artística seria 110 potencializada e maculada por sua atividade reflexiva.

Ora, se na estética de Hegel a morte da arte estaria condicionada exatamente a esta capacidade do homem moderno dos oitocentos de tornar-se um observador de si mesmo - algo que comprometeria a precondição para uma arte verdadeira, baseada na relação imediata entre a subjetividade do indivíduo e o objeto da fruição estética -, ao analisar o PIS segundo os mesmos termos, chegaríamos a conclusões notadamente diversas. Para Schiller, cujo espírito passional não foi o suficiente para afastá-lo de soluções conciliatórias, seria desejável, e até mesmo realizável no âmago do poeta, a coexistência entre o ingênuo e o sentimental. Todavia, não é este o ponto que nos interessa enfatizar aqui. Voltando à tese hegeliana, certamente Schiller discordaria veementemente de Hegel acerca do postulado do fim da arte, sobretudo porque para Schiller o advento da racionalidade e o caráter autorreflexivo do poeta moderno eram conquistas de um processo histórico no qual o homem se tornara cada vez mais autônomo em relação à natureza, por meio de sua consciência dela e de si próprio. A melancolia decorrente desta ruptura o faz querer retornar ao idílio, mas, impossibilitado de fazê-lo, transforma essa ausência em ideal. A arte, dessa forma, seria alçada ao seu mais alto patamar, no qual a beleza seria fruto não de um processo natural, mas da capacidade humana de pensar e conhecer

12 Reinhart Koselleck (2006) afirmou que, entre 1750 e 1850, mudanças significativas ocorreram nas sociedades europeias. Tais mudanças alteraram de forma profunda o modo de os homens se relacionarem com o tempo e compreenderem a história, de maneira que as transformações poderiam ser verificadas, até mesmo, na intensa reestruturação vocabular e conceitual desse período. 
a si mesma e seu mundo. Schiller não apenas almejava salvar a arte, bem como oferecera a seus contemporâneos uma das imagens da modernidade mais recorrentes na cultura ocidental que se seguiu à recepção de seu ensaio: a ideia do sujeito fraturado.

\section{Algumas considerações}

Schiller compartilhava com grande parte de seus colaboradores intelectuais as concepções de tempo e história que se apresentavam no bojo da difusão do cronótopo historicista, o qual pode ser também caracterizado pela concepção de que os homens "fazem a história". Esta noção - diretamente relacionada ao tempo histórico e sua temporalização, pois quando o futuro está aberto como possibilidade de construção e o sentido da história está depositado nele, os homens se sentem impelidos a construí-lo - pode ter sido a motivação de Schiller ao tornar públicas suas ideias em Poesia Ingênua e Sentimental.

Àquela época, pensar sobre as formas de produzir arte implicava não apenas a constituição de uma estética, mas também de um ideal de humanidade. As disputas em torno do que se convencionou chamar de classicismo e romantismo incitavam questões que ultrapassavam a produção artística, estavam em jogo também as ideias de progresso e civilização que, embora não fossem negadas por nenhum dos dois pontos de vista, seriam alvo de diferentes perspectivas. Então, na mesma medida em que Schiller se preocupava com um debate para além de sua contenda com Goethe, seu ensaio também tomou proporções maiores, influenciando o ambiente cultural alemão e legando à posterioridade uma síntese cultural que até hoje se faz presente na tradição ocidental.

O homem moderno sofria com o seu esfacelamento e buscava novamente sentir-se inteiro, assim como o era no quadro idealizado da humanidade tomado de empréstimo dos antigos. Porém, a simples emulação não resolveria o problema. Dessa vez, o homem deveria conciliar a harmonia com a natureza e sua autonomia de consciência. O poeta sentimental, nos disse Schiller, é aquele que reconhece o homem dilacerado, que busca reunificá-lo, mas que o faz com a plena consciência de estar travando uma batalha perdida. No entanto, essa constatação não significa a derrota da modernidade, pelo contrário, ela atestava sua predestinação, afinal toda poesia a partir de então deveria ser sentimental ou, em outros termos, moderna.

Essa Ideia da natureza como o "dever ser" da humanidade revela o entendimento do processo histórico como uma evolução, tal qual presente nas concepções historiográficas de Herder e Humboldt, que entendiam o conceito de evolução como amadurecimento, como uma transformação gradual e orgânica do elemento que já estava compreendido desde o início do processo. ${ }^{13}$ Se por um lado a natureza é o nosso dever ser, por outro a nossa experiência com a natureza não deve ser a mesma em todo o devir. No mundo antigo, a natureza era imprescritível à experiência humana, na modernidade o laço com a natureza

${ }^{13}$ Aqui nos é deveras cara a interpretação de Hayden White (2008) acerca do uso da metáfora na escrita da história de Herder. 
deve ser atado por intermédio da razão. Esse segundo momento, aos olhos de Schiller, seria superior, pois capaz de conduzir o homem à liberdade. Nesse dever ser, a cultura, razão da separação entre o homem e a natureza, tem o seu papel transformado, pois é através dela e, não de outra forma, que voltaremos à natureza. Por isso, não deveríamos lamentar a perda da naturalidade, ela se deu em nome de uma conquista maior: o primado da razão. A consciência humana produz sentido para o seu mundo, e não o contrário - Schiller concluiu a partir de categorias claramente kantianas. Este imperativo estético assume caráter de um imperativo político no pensamento do poeta alemão, o homem moderno dos escritos de Schiller é o sujeito que deve agir.

\section{Referências bibliográficas}

ARAUJO, Valdei Lopes de. História da historiografia como analítica da historicidade. História da historiografia, n. 12, p. 34-44, 2013.

- Observando a observação: sobre a descoberta do clima histórico e a emergência do cronótopo historicista, c. 1820. In: CARVALHO, José Murilo de. CAMPOS, Adriana Pereira. Perspectivas da cidadania no Brasil Império. Rio de Janeiro: Civilização Brasileira, 2011.

BERLIN, Isaiah. Le Mage du Nord, critique des Lumières. J. G. Hamann 1730-1788. Paris: Presses Universitaires de France, 1997.

CALDAS, Pedro Spinola Pereira. As dimensões do Historicismo : um estudo dos casos alemães. Revista OPSIS, v. 7, n. 9, p. 47-66, 2007.

DEJEAN, Joan. Antigos contra modernos: as guerras culturais e a construção de um fin de siècle. Rio de Janeiro: Civilização Brasileira, 2005.

ELIAS, Norbert. O processo civilizador: uma história dos costumes. Rio de Janeiro: Jorge Zahar Editor, 1994. v. 1.

GOETHE, Johann Wolfgang von; SCHILLER, Johann Christoph Friedrich von. Correspondência. Goethe e Schiller. São Paulo: Hedra, 2010.

GUMBRECHT, Hans Ulrich. Atmosfera, ambiência, Stimmung. Rio de Janeiro: Contraponto: Ed. PUC Rio, 2014.

Making sense in Life and Literature. Minneapolis: University of Minnesota Press, 1992.

Modernização dos sentidos. São Paulo: Ed. 34, 1998.

HERDER, Johann Gottfried. Idées sur la philosophie de I'histoire de I'humanité. Paris: Presses Pocket, 1991.

HUMBOLDT, Wilhelm von. Sobre a Tarefa do Historiador. Anima, ano 1, n. 2, 2001.

KANT, Immanuel. Crítica da faculdade do juízo. Rio de Janeiro: Forense Universitária, 2005. 
KOSELLECK, Reinhart. Crítica e crise: uma contribuição à patogênese do mundo burguês. Rio de Janeiro: EDUERJ; Contraponto, 1999.

. Estratos do tempo: estudos sobre história. Rio de Janeiro: Contraponto; PUC-Rio, 2014.

Futuro Passado: contribuição à semântica dos tempos históricos. Rio de Janeiro: Contraponto; Editora PUC-Rio, 2006.

LÖWY, Michael. SAYRE, Robert. Revolta e melancolia: o romantismo na contramão da modernidade. Petrópolis: Vozes, 1995.

MANN, Thomas. Goethe como representante da era burguesa. In: 0 escritor e sua missão. Rio de Janeiro: Jorge Zahar, 2012.

Os Famintos e outras histórias. Rio de Janeiro: Nova Fronteira, 2000.

OERGEL, Maike. Culture and identity: historicity in German literature and thought (1770-1815). Berlin: W de Gruyter GmbH \& Co, 2006.

PANOFSKY, Erwin. Idea: a evolução do conceito de belo. São Paulo: Martins Fontes, 1994.

PIKULIK, Lothar. Sentimiento de la naturaleza y desnaturalización del sentimiento. Sobre el concepto schilleriano de lo sentimental. In: JIRKU, Brigitte E.; RODRÍGUEZ, Julio (Ed.). El pensamiento filosófico de Friedrich Schiller. València: Univesitat de València, 2009.

RODRIGUES, Antonio Edmilson Martins; FALCON, Francisco José Calazans.

Tempos Modernos: ensaios de história cultural. Rio de Janeiro: Civilização Brasileira, 2000.

SCHLEGEL. Friedrich. Sobre el estúdio de la poesia griega. Madri: Ediciones Akal, 1995.

SCHILLER, Johann Christoph Friedrich von. A educação estética do homem. São Paulo: Iluminuras, 2002.

. Poesia Ingênua e Sentimental. São Paulo: Iluminuras, 1991.

SHARPE, Lesley. Schiller's Aesthetic Essays: two centuries of criticism. Columbia: Camden House, 1995.

SUZUKI, Márcio. Apresentação. In: SCHILLER, Johann Christoph Friedrich von. Poesia Ingênua e Sentimental. São Paulo: Iluminuras, 1991.

SZONDI, Peter. Poésie et Poétique de I'Idéalisme Allemand. Gallimard, 1991.

Weber. Max. A Ética Protestante e o "Espírito" do Capitalismo. São Paulo: Companhia das Letras, 2004.

WHITE, Hayden. Meta-história: a imaginação histórica do século XIX. São Paulo: Edusp, 2008. 